\title{
O GERENCIAMENTO DE RISCOS JUDICIAIS DAS EMPRESAS POR MEIO DE SOFTWARES
}

\author{
Fernanda Granja Cavalcante da Costa* \\ Eleandro Granja Costa Vanin e Hochmann ${ }^{*}$
}

\section{Resumo}

O gerenciamento de riscos é uma forma de buscar estabilidade nas atividades empresariais, o que é feito, contemporaneamente, por meio de softwares. Os softwares jurídicos tradicionais têm funções relacionadas à gestão de riscos pelo tratamento de informações processuais e sua apresentação em diferentes modos. Atualmente, contudo, há programas mais específicos para análise de riscos jurídicos, com uma gama bem maior de funcionalidades. O presente trabalho analisa esses softwares, concluindo que sua adoção traz resultados positivos, contribuindo para a governança corporativa.

Palavras-chave: riscos corporativos; governança corporativa; Business Intelligence; riscos jurídicos; softwares de gerenciamento.

\section{COMPANY LEGAL RISK MANAGEMENT THROUGH SOFTWARE}

\begin{abstract}
Risk management is a way to strive for stability in business activities. Risk analysis is nowadays made through the use of specialized software. This work aims to analyze legal risk management programs. Traditional legal software programs have functions related to risk management through the handling of procedural information and its presentation in varied ways. There are nowadays however more specific programs to analyze legal risks, with many more functionalities. This work examines such programs, concluding that its adoption brings positive results, which contributes to corporate governance.
\end{abstract}

Keywords: business risks; corporate governance; business intelligence; legal risks; management software.

\section{INTRODUÇÃO}

A busca pela segurança integra condição humana, e sempre está atrelada à questão do desenvolvimento tecnológico. Por um lado, grande parte do avanço científico adveio da

\footnotetext{
* Graduada pela Universidade Federal do Amazonas (UFAM). Especialista em direito constitucional. Mestre e doutoranda em direito pela universidade de Marília (UNIMAR). Mestranda em direito pela UNICURITIBA. Tabelião de Notas em Curitiba/PR.

* Graduado em Direito pela Universidade do Estado de Mato Grosso (UNEMAT). Especialista em Direito Notarial e Registral pela Universidade Cândido Mendes (UCAM). Especialista em Ciências Criminais pela Universidade Anhanguera/UNIDERP. Mestre e doutorando pela Universidade de Marília (UNIMAR). Tabelião de Protesto de Títulos em Belém/PA. Presidente do Instituto de Protesto de Títulos do Brasil - Seccional Pará.
} 
necessidade de segurança. Isso é fácil de perceber se se recordar que grande parte dos progressos da técnica e das ciências esteve relacionado com pesquisas em âmbito militar, essencialmente relacionadas à segurança nacional. Grande exemplo dessa realidade é a internet, surgida a partir de pesquisas do exército americano. Por outro lado, os avanços tecnológicos, mesmo quando motivados por outros fatores, sempre acabam por refletir em mais recursos capazes de gerar segurança. Assim, por um motivo ou outro, sempre se tem a sensação de que os progressos têm algo a ver com segurança.

O direito é realidade multifacetada, com múltiplas funções - efetivar direitos humanos, distribuir a Justiça, garantir a paz social, etc. - dentre as quais está ser uma tecnologia de resolução de conflitos. E como toda tecnologia, visa a garantir segurança. Historicamente, a busca da segurança pelo direito tem a ver com a coletividade (como no direito penal, por exemplo), ou com as relações individuais.

Neste último setor, a segurança tem a ver com a salvaguarda de direitos das partes diante de imprevistos relacionados ao comportamento da outra parte, como o inadimplemento; ou relacionados com causas externas às relações interpessoais. Exemplo de garantia em face do comportamento alheio é o princípio do pacta sunt servanda e seus desdobramentos. Em relação ao que é externo, tem-se o contrato de seguro, por exemplo, que oferecem uma indenização pela ocorrência de sinistros.

Mas recentemente, no âmbito coorporativo, a segurança é buscada na análise de riscos. Não se trata de assegurar danos após sua ocorrência, mas desenvolver estratégias para que os danos não sejam gerados. E isso diz respeito à gestão de riscos: analisar as causas dos riscos da atividade e possíveis soluções.

Paralelamente ao surgimento da análise de riscos, o mundo contemporâneo vive a Era Digital. Como resultado do avanço exponencial de diversas tecnologias, sobretudo relacionadas às mídias digitais, o mundo vivencia a chamada Quarta Revolução Industrial (também chamada de Revolução Tecnológica). A aplicação das novas tecnologias promove mudanças profundas nos modelos de negócio, sobretudo como resultado da larga aplicação de softwares e maquinário cada vez mais automatizado em seus processos de produção.

Assim, o presente trabalho analisa a junção entre essas duas realidades: a técnica de gestão de risco nas empresas, como avanço que resulta da busca por segurança no ambiente coorporativo; e o uso de softwares de gestão de riscos, como contrapartida que os avanços da técnica sempre acabam trazendo no incremento da segurança. Sendo o escopo deste trabalho 
relacionado ao direito, é realizado um corpo relativo aos riscos geridos. Assim, o trabalho terá maior enfoque em softwares de gestão de riscos jurídicos.

\section{O GERENCIAMENTO DE RISCOS NO ORDENAMENTO BRASILEIRO}

Em geral, o desenvolvimento clássico do Direito e suas formas de aplicação não se voltaram para a gestão de riscos das empresas, tanto é que a maior parte dos profissionais da área não se orienta nesse sentido. Todavia, os paradigmas da Nova Economia Institucional mostram-se como a chave de interface entre o Direito e a Economia na gestão estratégica dos riscos legais para a governança da empresa.

\subsection{A evolução do gerenciamento de riscos em geral}

Historicamente, a gestão de risco nos negócios era associada à ideia de limitação das perdas financeiras do capital investido na atividade. Em geral, os riscos operacionais são riscos jurídicos incidentes sobre a economia, de modo que, a avaliação estratégica da "exploração econômica da atividade privada"1 apresenta quais riscos devem ser assumidos e quais devem ser mitigados. Se o fenômeno empresarial possui natureza jurídica e econômica, é evidente a importância do Direito em sua explicação.

As incertezas e dificuldades nos primórdios da vida humana conduziram ao desenvolvimento de formas de mitigação de riscos, sobretudo físicos, para que o homem pudesse, cada vez mais, satisfazer duas necessidades. Se na pré-história o risco físico é mitigado com a invenção de instrumentos de caça, os primeiros mercadores que se aventuravam em cruzadas pela compra e venda de especiarias eram recompensados com o enriquecimento. $\mathrm{O}$ desenvolvimento mais intenso do comércio levou à criação da moeda e o lucro deixa de recompensar o risco físico e passa a recompensar o risco econômico da própria atividade $^{2}$.

Um dos primeiros contratos de mitigação de riscos é o contrato de seguro. Em suas primeiras manifestações revela que os riscos do contrato eram ligados aos riscos da navegação mercantilista. É nesse período, também, que surge a abstração "personalidade jurídica". Foi a dissociação entre a pessoa do empresário e da empresa em si que permitiu a proteção do investimento e da individualização dos riscos na figura da pessoa jurídica. 
Na nova proposta de análise do papel da empresa, sugerida por Ronald Coase, surgem duas formas de análise da interface entre o Direito e a Economia: a Análise Econômica do Direito e a Nova Economia Institucional. Para a primeira, trata-se de verificar a eficiência normativa do Direito, "a partir da análise de casos concretos e de aplicação da eficiência econômica às instituições jurídicas"3. . A segunda, partindo da influência do Direito sobre o mercado e sobre as empresas, "prioriza a análise da eficiência, porém sob a perspectiva dos custos de transação na organização da empresa e dentro de um contexto institucional"4.

A evolução do pensamento econômico conduziu à visão da empresa como protagonista do modelo alternativo aos mercados, superando-se a visão do empresário como agente hiper-racional e propondo um modelo que submeta a responsabilidade da empresa aos riscos de fato assumidos em sua atividade. Se o Judiciário não favorece essa leitura, cumpre à gestão estratégica dos riscos jurídicos adotá-la, estabelecendo expectativas realistas sobre a atividade empresarial e abrindo-se mão de uma ilusória hiper-racionalidade em nome de valores concretos como "previsibilidade e pró-atividade"

\subsection{A delimitação normativa do gerenciamento de riscos}

Como se sabe, o mercado existe com respaldo em uma ordem jurídica que confere segurança às relações nele travadas, criando o ambiente de confiança necessário às trocas mercantis. No Brasil, a ordem econômica tem seus fundamentos elencados no art. 170 da Constituição Federal. No que interessa à temática dos riscos, frisa-se os princípios da livre iniciativa (caput), da propriedade privada (inciso II), da função social da propriedade (inciso III), da livre concorrência (inciso IV), da defesa do consumidor (inciso V) e da defesa do meio ambiente (inciso VI).

Uma vez que os riscos jurídicos se ligam fundamentalmente ao descumprimento de preceitos legais, é possível deduzir, a partir dessas disposições do art. 170 da CF, as grandes fontes de riscos para as empresas. Os riscos mais obviamente perceptíveis são atividades que gerem danos ambientais, ao consumidor, à livre concorrência. Mas também é possível concluir que más práticas de empreendimento comprometem a qualidade do mercado, prejudicando a livre iniciativa e a propriedade privada alheias. Por fim, em todas as situações, a ofensa ao Direito é um descumprimento da função social da propriedade.

O estatuto jurídico da empresa pública e da sociedade de economia mista também 
contempla diversas regras sobre gestão de riscos. Com efeito, no art. $6^{\circ}$ da Lei $n^{o}$ 13.303/2016, consta a necessidade de as empresas estatais observarem "regras de governança corporativa, de transparência e de estruturas, práticas de gestão de riscos e de controle interno, composição da administração". Adiante, a lei prevê algumas medidas práticas para possibilitar a gestão de riscos, tais como a "implementação cotidiana de práticas de controle interno" (art. $9^{\circ}$, I) e a criação de "área responsável pela verificação de cumprimento de obrigações e de gestão de riscos" (art. 9 ${ }^{\circ}$, II).

Em caráter específico, a principal disciplina jurídica sobre a gestão de riscos se encontra nas resoluções do Conselho Monetário Nacional do Banco Central. Para Salloum Silva $^{6}$, embora tais normas se dirijam ao mercado financeiro, são aplicáveis a outros setores da economia. Atualmente, vige a Resolução no 4.557/2017 que "dispõe sobre a estrutura de gerenciamento de riscos e a estrutura de gerenciamento de capital”.

É dever das instituições financeiras implementar estruturas de gerenciamento de riscos (art. $\left.2^{\circ}, I\right)$ que sejam compatíveis com o modelo de negócio e de suas operações (art. $2^{\circ}$, $\left.\S 1^{\circ}, \mathrm{I}\right)$. Tais estruturas devem ser "proporcionais à dimensão e à relevância da exposição aos riscos" (art. $2^{\circ}, \S 1^{\circ}$, II), "adequadas ao perfil de riscos e à importância sistêmica da instituição" (art. $2^{\circ}, \S 1^{\circ}$, III) e "capazes de avaliar os riscos decorrentes das condições macroeconômicas e dos mercados em que a instituição atua" (art. $2^{\circ}, \S 1^{\circ}$, IV).

A contabilização relacionada à gestão de riscos jurídicos encontra respaldo no Plano Contábil das Instituições do Sistema Financeiro Nacional ${ }^{7}$ (Cosif), também idealizado pelo Banco Central. O Consif determina, em suas normas básicas, que as operações de crédito devem ser classificadas segundo seu nível de risco, conforme uma ordenação crescente de nove categorias ${ }^{\mathrm{i}}$. Nesse sentido, "a classificação da operação no nível de risco correspondente é de responsabilidade da instituição detentora do crédito e deve ser efetuada com base em critérios consistentes e verificáveis, amparada por informações internas e externas" (Item 6.2.2).

Essa classificação não diz respeito exatamente ao risco de a instituição financeira sofrer danos em razão de seu próprio agir, mas em razão da possibilidade de inadimplemento. A classificação deve contemplar uma série de aspectos. Em relação ao devedor e seus garantidores, deve avaliar fatores como situação financeira, endividamento, capacidade

\footnotetext{
${ }^{\mathrm{i}}$ Item 6.2.1: "1 - As instituições financeiras e demais instituições autorizadas a funcionar pelo Banco Central do Brasil devem classificar as operações de crédito, em ordem crescente de risco, nos seguintes níveis: nível AA; nível A; nível B; nível C; nível D; nível E; nível F; nível G e nível H.”
} 
de geração de resultados, fluxo de caixa; administração e qualidade de controles, pontualidade e atrasos nos pagamentos, dentre outros. Em relação à operação, a instituição deve se atentar ao valor, à natureza e finalidade da transação e às características das garantias (particularmente quanto à suficiência e liquidez).

Em tempo: é fato que o risco jurídico ora analisado é diverso do que em regra ocorre, pois as empresas se preocupam com os riscos das suas infrações a normas legais, e não das infrações causadas por outrem. Todavia, essa normativa é pertinente ao presente trabalho, por duas razões. A uma, porque seus critérios são interessantes para analisar situações riscos que poderiam ser levadas em conta pelas empresas em relação a si mesmas. Ou seja, a partir da normativa do Banco Central, as empresas têm critérios para definir os riscos de suas próprias operações. A duas, porque o inadimplemento de terceiros, sendo um fenômeno obrigacional e de responsabilidade civil, é risco jurídico de extrema relevância no ambiente de mercado.

\section{O GERENCIAMENTO DE RISCOS JURÍDICOS}

O gerenciamento de riscos jurídicos abarca sua identificação, a partir da coleta de dados, bem como a elaboração de estratégia de prevenção e mitigação destes riscos, a partir do que se constatou. Em outras palavras, trata-se de identificar os focos dos problemas jurídicos que acometem determinada empresa para orientar soluções eficazes em seus negócios. Ao fim das contas, reduz-se os custos, isto é, o passivo jurídico gerado pela atividade empresarial.

\subsection{A gestão de riscos jurídicos e a governança coorporativa}

Nos dias atuais, em paralelo à necessidade de gestão jurídica dos riscos, é inevitável a adoção integral de uma governança corporativa, exigindo-se a submissão empresarial a certas condutas, procedimentos e à internalização de princípios compatíveis com a responsabilidade na prestação de contas e respeito à legislação ${ }^{8}$.

Pesquisas demonstram que a fraca governança corporativa torna o ambiente propício às fraudes, resultando imprescindível a atuação dos departamentos jurídicos da empresa na avaliação dos ativos e passivos garantindo previsibilidade ao setor financeiro. Em síntese, os pilares da governança corporativa são: transparência, equidade, prestação de contas e 
responsabilidade corporativa. O advogado é alçado à posição de destaque no compliance, pois o setor jurídico informa as disposições legais pertinentes e reprime o deslinde de novos litígios envolvendo a empresa ${ }^{9}$.

A Lei Sarbannes Oxley, de 2002, é um exemplo de instrumento jurídico ligado à governança corporativa e, com o objetivo de recuperar a confiança empresarial, estabeleceu como exigência o respeito aos princípios de transparência, conformidade legal e práticas alinhadas à ética e sustentabilidade negocial. No Brasil, esse momento se revelou com o surgimento do Código do Instituto Brasileiro de Governança Corporativa (IBCG) e da Comissão de Valores Mobiliários $(\mathrm{CVM})^{10}$.

Se a governança corporativa abarca uma série de medidas e procedimentos administrativos com o objetivo de melhorar a gestão da empresa, a gestão de riscos jurídicos é parte desse instrumento necessário. A detecção de riscos corporativos é importante instrumento de governança corporativa, que pode ser definida pelo "o conjunto de práticas administrativas para otimizar o desempenho das empresas - com seus negócios, produtos e serviços - ao proteger, de maneira equitativa, todas as partes interessadas (...) facilitando o acesso às informações básicas da empresa e melhorando o modelo de gestão ${ }^{11}$.

O surgimento de "mecanismos de proteção ao risco da perda do capital investido" 12 foi o que abriu portas para o protagonismo do mercado de capitais na economia mundial, uma vez que a mitigação de riscos depende de instrumentos jurídicos. A análise do risco jurídico depende de uma equipe de juristas especializada e pronta para assessorar as atividades das instituições financeiras ${ }^{13}$. Não apenas deve se resumir aos procedimentos internos para o cumprimento da legislação, mas também às necessidades do funcionamento da própria empresa dentro do sistema jurídico em que se insere. Substitui-se a autorregulação por um sistema de gestão interna que visa lidar com os efeitos do ambiente jurídico ${ }^{14}$.

\subsection{Fontes e delimitação de riscos jurídicos}

O risco operacional diz respeito à "possibilidade de ocorrência de perdas resultantes de falha, deficiência ou inadequação de processos internos, pessoas e sistemas, ou de eventos externos" e que "inclui o risco legal associado à inadequação ou deficiência em contratos firmados pela instituição, bem como a sanções em razão de descumprimento de dispositivos legais e a indenizações por danos a terceiros decorrentes das atividades desenvolvidas pela instituição" $"$. 
Os riscos decorrem de múltiplas fontes, que variam conforme a natureza da atividade. Os riscos jurídicos, em geral, são relacionados ao descumprimento de normativas aplicáveis, oriundas de fontes estatais (legais, administrativas) ou não estais (moral, costumes, auto regulação setorial). A atividade também pode gerar danos ambientais, trabalhistas, consumeristas, de saúde, de segurança etc., hipóteses em que podem haver a responsabilização civil, penal e administrativa da empresa.

A despeito da imprescindibilidade da gestão de riscos, algumas questões são passíveis de interpretação, abalando a segurança jurídica empresarial. Decisões judiciais que responsabilizam as empresas por eventos absolutamente estranhos ao risco inerente à atividade econômica desenvolvida, por exemplo, acabam ferindo as expectativas da empresa, especialmente, de caráter econômico ${ }^{16}$.

O corpo jurídico da empresa é de suma importância para determinação da natureza da contingência e dos valores a serem desembolsados. A pendência sobre declaração de constitucionalidade (ou inconstitucionalidade) de uma norma pelo STF que crie obrigação tributária, por exemplo, terá como consequência o correto provisionamento do recurso que eventualmente será devido pela empresa ${ }^{17}$.

A gestão do risco empresarial não pode depender de uma visão jurídica puramente reativa aos fenômenos, responsiva aos fatos. Isso porque, antes de tudo, tal gestão terá um papel "estratégico, preditivo, interdisciplinar e inserido no contexto da organização e da operacionalização do negócio empresarial" 18 .

$\mathrm{Na}$ prática, trata-se da coleta, da triagem e da classificação de informações da atividade que, de algum modo, possam contribuir para a delimitação dos riscos. A partir disso, há a hierarquização de dados, o que torna possível estabelecer as associações corretas de causa e efeito entre determinada atitude da empresa e o risco gerado e, por sua vez, entre esse risco e a lesão ao negócio. A título de exemplo: como ocorreu com a empresa Vale do Rio Doce, o não cumprimento de normas técnicas sobre acondicionamento de resíduos minerais (atitude) pode criar uma situação de instabilidade (risco) capaz de gerar danos sociais e ambientais e o respectivo dever responsabilizes civil e penal (lesão).

Com a correta identificação, há uma consequência ordenação dos riscos de acordo com seu nível de criticidade, isto é, conforme o potencial lesivo que apresentam. Esse diagnóstico permite, de modo preciso, organizar as possíveis soluções, elegendo prioridades conforme maior potencial lesivo do risco que se pretende eliminar. 
As soluções, obviamente, envolvem respostas aos problemas emergenciais. Mas não apenas. Também existe a adoção de medidas profiláticas, capazes de criar um ambiente propício ao desenvolvimento do negócio já livre dos elementos causadores de riscos que poderiam surgir.

\section{OS SOFTWARES DE GERENCIAMENTO DE RISCOS JURÍDICOS}

Esses avanços geraram a Era Digital, que se afeta todas as áreas de estudo e trabalho. E o Direito não poderia deixar de ser influenciado por isso, mesmo não sendo uma área propriamente tecnológica. A rotina dos operadores do direito em geral se modificou muito com o desenvolvimento de equipamentos diversos - microcomputadores facilitaram pesquisas e peticionamento; scaners portáteis contribuíram para o trabalho com documentos; smartphones agilizaram a comunicação da equipe e com clientes; etc.

Porém, o maior impacto se deu no âmbito dos softwares. E é cediço que o uso de softwares é necessariamente relacionado à internet. Hoje em dia, até mesmo os aparelhos eletrodomésticos são conectados à web, não se concebendo como seria diferente no caso dos programas de gerenciamento de processos corporativos.

Tendo em vista os riscos inerentes à rede mundial de computadores, é de se questionar o largo uso de softwares não poderia contribuir para um acréscimo de riscos às empresas, no tocante à segurança de dados. Se uma análise empírica se mostra inviável, percebe-se que a legislação brasileira sobre o uso da internet, contudo, tem avançado significativamente.

\subsection{O ambiente institucional propício ao uso de softwares e da internet}

Em 2014 foi publicado o Marco Civil da Internet (Lei $n^{\circ}$ 12.965/2014), estabelecendo princípios, garantias, direitos e deveres para o uso da internet no Brasil. Em 2018, publicou-se a Lei Geral de Proteção de Dados (Lei n 13.709/2018), que atualiza o Marco Civil e consolida a regulamentação, sobretudo, do direito fundamental à privacidade contemplado no art. $5^{\circ}, \mathrm{X}$, da Constituição Federal.

Essa normativa cria o ambiente institucional propício à ampliação do uso de softwares em todos os âmbitos. A partir dessas leis, há um sistema princípios que orientam a conduta dos agentes na web, prevendo seus direitos e devedores, bem como sua 
responsabilidade em caso de ilícitos e danos. Nos termos do Marco Civil, tratam-se de garantias de "preservação da estabilidade, segurança e funcionalidade da rede" (art. 30, V, Lei $\left.\mathrm{n}^{\mathrm{o}} 12.965 / 2014\right)$.

No mais, as garantias da Lei Geral de Proteção de Dados Pessoais (LGPD). É fato que a repercussão das garantias relativas a dados pessoais envolva em sua maior parte os dados de pessoas humanas, quando abusivamente utilizados por empresas ou pelo Estado. Todavia, as pessoas jurídicas também têm seus direitos garantidos no tocante à proteção de dados.

Com efeito, a LGPD prevê, dentre os fundamentos da disciplina da proteção de dados pessoais o desenvolvimento econômico (art. 2º, V, Lei $\mathrm{n}^{\mathrm{o}}$ 13.709/2018) e a livre iniciativa (art. $2^{\circ}$, VI, Lei ${ }^{\circ}$ 13.709/2018). Além disso, já no Marco Civil constava que, no cumprimento de seu dever de fornecer informações prestadas para garantir o direito de acesso $^{i i}$ dos titulares de dados pessoais, as empresas têm resguardado seu "direito de confidencialidade quanto a segredos empresariais" (art. 10 ${ }^{\circ} \S 4^{\circ}$, Lei no $12.965 / 2014$ ).

Outro aspecto interessante é a possibilidade das empresas participarem de uma "governança multiparticipativa" para o desenvolvimento da internet, em conjunto com o Poder Público, a sociedade civil e a comunidade acadêmica (art. 24, I Lei no 12.965/2014). Ou seja, o setor empresarial tem a faculdade de intervir de forma a garantir que o ambiente da web seja protetivo e satisfatório à realização de seu objeto social.

\subsection{Os softwares no cotidiano do Direito e suas funções}

Quando se pensa em softwares jurídicos, o que primeiro vem à mente são utilitários para os próprios advogados em escritórios, ou para equipes do departamento jurídico das empresas. Tradicionalmente, estes programas possuíam funções limitadas ao armazenamento de dados relacionados ao contencioso processual (nome de partes, número dos autos, andamentos processuais). Nesse âmbito, a função mais relevante de tais programas estava no controle de prazos preclusivos.

O avanço tecnológico foi paulatinamente acrescentando funções aos softwares jurídicos e aumentando o grau inteligência artificial envolvida. Isso gerou uma especialização

\footnotetext{
ii “Art. 10. A guarda e a disponibilização dos registros de conexão e de acesso a aplicações de internet de que trata esta Lei, bem como de dados pessoais e do conteúdo de comunicações privadas, devem atender à preservação da intimidade, da vida privada, da honra e da imagem das partes direta ou indiretamente envolvidas".
} 
de setor, sendo possível classificar os softwares jurídicos em duas grandes categorias, de acordo com seu público algo: (a) os softwares utilizados por departamentos jurídicos de empresas; e $(b)$ os utilizados por escritórios de advocacia. É fato que alguns programas apresentam variações que buscam atender a ambos os setores, mas a realidade é que, ainda assim, o mercado é dividido dessa maneira, o que se revela pelo cotidiano da prática jurídica.

A partir de pesquisas empíricas em que foram entrevistados centenas de advogados, o site Gestão Jurídica Empresarial (Gejur) - vinculado à a rede Inteligência Jurídica (Intelijur) - chegou a uma lista dos softwares mais utilizados por cada grupo, para os anos de 2012 e $2015^{19}$. Em 2017, a Intelijur repetiu a pesquisa, dessa vez expandindo para 1400 o número de entrevistados $^{20}$. As pesquisas são ricas em informações de grande interesse prático, mas não comportam análise exaustiva neste trabalho. No que ora interessa, para os anos de 2012, 2015 e 2017, percebe-se algumas constantes dignas de nota.

No âmbito dos departamentos jurídicos de empresas, o software Espaider se destaca por ser cada vez mais utilizado ao longo dos anos pelos profissionais (19,9\% dos entrevistados em 2012; 25,1\% em 2015; e 27,9\% em 2017). Em seguida, tem-se o RR Jurídico, que cresceu vertiginosamente sua utilização de 2012 (4,5\%) para 2015 (23,6\%), mantendo a segunda colocação em preferência em 2017 (23\%).

Nos escritórios, por sua vez, destaca-se o CPJ-Preâmbulo, que de quarto lugar em 2012, utilizado apenas por 5,9\% dos entrevistados, para o primeiro lugar isolado em 2015 , com utilização por $39,5 \%$ destes. O software manteve a liderança em 2017 , sendo declarado como preferência de 29,4\% dos profissionais. O CP-PRO era o líder em 2012 com 22,7\% de preferência, mas passou à segunda colocação em 2015 com queda significativa de usuários (8,8\%). Em 2017 a pesquisa mostra que em segundo lugar estão empatados vários softwares, dentre eles o CP-Pro, com preferência de $19,9 \%$ dos entrevistados ${ }^{21}$.

A partir desses resultados, têm-se os quatro softwares jurídicos de maior procura no mercado brasileiro atualmente. Para compreender o estágio atual do setor, portanto, convém uma breve análise de suas funções.

O Espaider ${ }^{22}$ em modalidade corporativa apresenta as funções de: $(i)$ análise de faturas emitidas por escritórios parceiros da empresa; (ii) Business Intelligence, para dar subsídios a decisões a partir de várias formas de apresentação de dados (planilhas, gráficos e análises); (iii) gestão de casos em consultivo, contencioso, contratos e títulos em cobrança; 
(iv) controle de documentos digitais; (v) controle de propriedade da empresa, material (imobiliária) e imaterial (marcas, patentes, domínios).

O RR Jurídico ${ }^{23}$ funções semelhantes, organizadas em três grandes áreas: gestão de contratos; gestão de documentos (na qual está incorporada a gestão de propriedade imobiliária e imaterial), e a gestão de processos. Também apresenta a funcionalidade de gerar relatórios ${ }^{24}$ (em tela ou em Excel), com informação selecionadas a partir de contratos ou processos, apresentando indicadores, gráficos e análises.

O $\mathbf{C P J}^{25}$ apresenta "robôs de automação", para realizar tarefas repetitivas, extrair informações e integrar o CPJ com outros softwares do mercado. Além disso, com uso de inteligência artificial, possibilita a classificação de publicações, a fim de otimizar o fluxo de trabalho. Também possibilita a integração entre o financeiro e o processual, "garantindo o acompanhamento de honorários e custas, contas a pagar e a receber" ${ }^{26}$. Por fim, emite relatórios e fornece indicadores (dashboards). O CP-PRO ${ }^{27}$ tem praticamente as mesmas funções, conforme se constata pela leitura do site da empresa fornecedora.

Como se percebe, os quatro programas mais utilizados por operadores do direito no Brasil apresentam funcionalidades similares, adaptadas ao seu público alvo primordial. Evidentemente, ainda existe uma plêiade de outros programas de elevada utilidade prática. $\mathrm{E}$ não apenas existem concorrentes aos programas ora listados, mas também outros tantos que apresentam funções totalmente diversas. A exposição nesse caso é amostral, e tem como objetivo esclarecer o cenário geral dos softwares jurídicos hoje mais usados no Brasil.

\subsection{Os softwares de gerenciamento de riscos jurídicos e sua aplicação}

No que diz respeito à análise de riscos, ela diz respeito às funcionalidades relacionadas ao chamado Business Intelligence, que envolve o tratamento de informações e sua apresentação em diferentes modos, através de gráficos, relatórios e indicadores. É o que dizem os desenvolvedores do Espaider, para quem o Business Intelligence fornece subsídios seguros para o que chamam de legal analysis ${ }^{28}$.

Por sua vez, a Preâmbulo apresenta a análise de riscos como uma das funcionalidades de seus sistemas de Business Intelligence. Assim, os "indicadores do CPJAnalytics" seriam ferramentas que permitiram "acompanhar os processos que já tiveram decisões proferidas, qual o risco envolvido, a média de assertividade, e se a decisão foi favorável ou desfavorável" 29 . Como se vê, trata-se de uma análise circunscrita aos riscos de 
sucesso envolvidos no âmbito contencioso processual. Todavia, segundo a empresa, esses indicadores poderiam otimizar as decisões de gestores, pelo fornecimento de informações mais precisas e dispostas de maneira visualmente diferenciada.

A Thomson Reuters fornece no mercado o programa Legal One, que se propõe a “apoiar os departamentos jurídicos das corporações garantindo uma gestão jurídica eficiente, que auxilia os profissionais a tomarem as melhores decisões no que se refere a contencioso, passivo processual, gestão de contratos, consultivo, imobiliário e procurações de forma segura e rápida para elevar os resultados da corporação, reduzir os custos, fornecendo provisionamentos mais assertivos e assim tornando o departamento mais estratégico" ${ }^{30}$. No que tange à análise de riscos, o programa oferece ferramentas relacionadas a Compliance com as principais normas de segurança, como Sarbanes-Oxley; Gestão do ciclo de vida dos contratos e Mitigação de riscos financeiros e legais existentes nas relações da empresa.

\subsubsection{Análise de casos}

De todo modo, a simples menção às funcionalidades desses programas não permite a compreensão dos efeitos práticos desses instrumentos. Por outro lado, uma análise teórica dos mecanismos internos dos softwares se mostra inviável, pois demanda abordagem de conteúdos que fogem ao âmbito do direito. Assim, entende-se que o que o mais interessante aos propósitos deste trabalho é analisar os reflexos do uso de alguns destes produtos para empresas em concreto, o que permite antever a eficácia de seu uso.

Para tanto, foram comparados casos concretos disponibilizados pelas fornecedoras de softwares, de análise de riscos em algumas corporações. Em que pese se trate de pessoas jurídicas de natureza diversa, percebe-se que a adoção desses softwares possibilitou um maior controle de documentação, hierarquização de acessos ao sistema, segurança e sigilo de informações no âmbito de seus respectivos processos operacionais.

O Convex Legal Analytics é um programa que auxilia no contingenciamento de riscos jurídicos, atuando tanto para escritórios quanto para departamentos jurídicos. Segundo informações da Softplan, desenvolvedora do software, o Convex opera dando apoio na organização, interpretação e análise dos dados e informações públicas nos sites de tribunais, apresentando-os de maneira "dinâmica e fácil de visualizar". Segundo a Softplan, essas informações, detalhadas e confiáveis, fornecem subsídios para que o cliente "gerencie seus processos de forma mais racional, otimizando seus recursos" $" 31$. 
Especificamente, o programa faz uma varredura de peças processuais e decisões, para identificar padrões que sirvam aos propósitos da empresa. Ainda, com o recurso chamado "volumetria", o Convex compara processos e desempenhos jurídicos de bancas advocatícias, oferecendo "uma visão completa e atualizada para entender o que aconteceu e o que acontecerá, possibilitando a criação de melhores estratégias”. O funcionamento prático do programa é mais perceptível pela leitura de alguns de seus $\operatorname{cases}^{32}$.

Em relação à empresa Amil, foi aplicada uma técnica chamada "Análise Semântica Latente". Inicialmente a empresa desenvolveu um "dicionário semântico" contendo a definição de cada tema, com o qual alimentou o software. Em seguida, desenvolveu um algoritmo de classificação que "varreu as petições iniciais dos processos", realizando o cotejo entre o conteúdo dessas peças e os termos constantes no dicionário. A partir disso, foi possível selecionar, em um conjunto de milhares de feitos, os processos que poderiam ensejar temas de Incidente de Resolução Repetitiva.

Em relação ao grupo Cosan, foi realizado um saneamento em toda sua base de processos judiciais. Aplicando-se a técnica de "processamento de linguagem natural" nas petições iniciais, foram classificados todos os processos a partir de pedidos, objetos de ação e causa raiz nos critérios, e regras de negócio específicos do Grupo Cosan. A partir disso, foram estabelecidos marcadores para vincular os processos a cada um dos segmentos de negócio do grupo, tecendo análises comparativas e probabilísticas de êxito e desempenho relacionadas aos de escritórios contratados pela Cosan para atuar nos feitos.

Em relação à FIESP. foi criada, junto com especialistas da empresa, um observatório da Reforma Trabalhista. Nesse contexto, o software fez uma varredura de todas as 672 mil de decisões de processos judiciais nos Tribunais Regionais do Trabalho de São Paulo e Minas Gerais, analisando todas as decisões. A partir disso, foram classificadas em relação ao modo aplicação de alguns artigos da Lei $n^{\circ}$. 13.467/2017. O resultado foi "uma ampla e completa análise dessas decisões, as partes envolvidas, unidades judiciais e tipos de processos".

Outra fornecedora de uma linha de softwares de gestão de riscos é a empresa SoftExpert, que atua em parceria com a TGN Brasil. Segundo o site institucional das empresas $^{33}$, a SoftExpert fornece soluções para "gestão da excelência e conformidade empresarial”, ao passo que a TGN Brasil automatiza processos de gestão de documentos, negócios, indicadores diversos, riscos, etc. A empresa fornece uma série de programas, direcionados à gestão dos mais variados elementos relacionados ao mundo coorporativo, tais 
como processos de negócio, recursos humanos, desempenho, riscos, segurança, etc.

O primeiro caso de refere ao uso do software SoftExpert Excellence Suite (SE Suite), pela Companhia Riograndense de Saneamento (Corsan). Com o advento da Lei $\mathrm{n}^{\mathrm{o}}$ 13.303/2016, essa sociedade de economia mista se viu na contingência de adequar sua operacionalidade às exigências legais. Diante disso, empresa adotou uma série de medidas, como a criação da Superintendência de Controles Internos, Gestão de Riscos e Compliance (SUCIR). E para otimizar esses processos, adotou o software SE Suite.

Em síntese, o programa funciona pelo mapeamento de processos operacionais da empresa, condensando as informações pertinentes e as apresentando de maneira simples e acessível a todos os colaboradores. Dente outras consequências, isso possibilitou a "identificação e tratamento dos riscos inerentes ao escopo do projeto", além de poupar gastos com treinamento de pessoal. Na opinião do Superintendente da SUCIR, Allan Machado Kovalscki $^{34}$, o uso do software contribuiu significativamente para que a empresa cumprisse as determinações da Lei no 13.303/2016 "facilitando também a disseminação dos resultados e as análises imediatas dos riscos que podem comprometer o negócio" 35 .

Situação similar envolveu a cooperativa Unimed Vitória, que adotou o programa Gestão da Qualidade Empresarial (EQM) para automatizar rotinas e aumentar a eficácia na gestão de documentos. Dentre outros motivos, a cooperativa recorreu ao software tendo em vista seu porte - de uma das 10 maiores cooperativas do país milhares de associados, colaborares e beneficiários - e a necessidade de se conformar com os requisitos de Sistema de Gestão de Qualidade (SGQ), necessários para recebimento de selos de excelência como o ISO $9001^{36}$. Adotando o software, foram automatizados "o roteiro de elaboração, revisão e aprovação de documentos, com acompanhamento em tempo real de pendências no fluxo da documentação" 37 . Na opinião de Heloisa Rodrigues Queiroz, coordenadora de gestão da qualidade e processos da cooperativa, a adoção do EQM simplificou o monitoramento da validação de documentos, aumentando a segurança e sigilo das informações.

Como se vê, embora não haja relação tão direta com os riscos jurídicos, como no caso da Corsan, o reflexo na área jurídica é facilmente dedutível. No caso, não se trata de prever, mas de diminuir os riscos jurídicos, através da adoção de medidas de compliance. A agilidade no processamento de documentação facilita a gestão de procedimentos no âmbito dos planos de saúde, o que certamente contribui para evitar a judicialização por parte de beneficiários, notoriamente o maior passivo jurídico das cooperativas médicas. Além disso, a 
segurança nas informações diminui o risco de indenizações por danos à privacidade.

A E-Xyon Tecnologia é uma empresa que oferece diversos produtos tecnológicos relacionados ao direito. Dentre eles, está o diagnóstico de risco jurídico que, segundo a empresa acarreta uma série de benefícios tais como: a consolidação da carteira judicial; a redução do contingenciamento para riscos jurídicos; identificação das causas raiz de demandas jurídicas; o estabelecimento de indicadores de desempenho jurídicos (KPI's); o suporte das operações de due diligence e fusões e aquisições (M\&A); e a implementação de ações corretivas para mitigação de risco jurídico ${ }^{38}$.

Segundo consta em seu site, a E-Xyon foi contratada pelo banco $\mathrm{BMG}^{39}$ para o serviço de "captura antecipada de processos", serviço este que possibilita ao banco se antecipar à notificação judicial em mais de 100 dias, dando maior tempo de coleta e subsídios para instrução da defesa, para políticas de acordo mais eficazes ou identificação de advogados agressores contumazes.

\section{CONCLUSÃO}

O progresso da técnica é ao mesmo tempo uma consequência e uma causa da segurança, cuja busca integra a condição humana. Uma das formas de as empresas buscarem segurança é prevendo e gerenciando os riscos de sua atividade. Na sociedade contemporânea, marcada pela Revolução Tecnológica, a análise de riscos aplica das novas tecnologias promove mudanças profundas nos modelos de negócio, sobretudo como resultado da larga aplicação de softwares. O escopo deste trabalho foi a análise dos softwares de gestão de riscos jurídicos.

Para tal gestão é inevitável a adoção integral de uma governança corporativa, exigindo-se a submissão empresarial a certas condutas, procedimentos e à internalização de princípios compatíveis com a responsabilidade na prestação de contas e respeito à legis lação. Uma vez que os riscos jurídicos se ligam fundamentalmente ao descumprimento de preceitos legais, é possível deduzir, a partir dessas disposições do art. 170 da CF, as grandes fontes de riscos para as empresas.

Em face disso, há o imperativo pela segurança, que integra a busca pela governança corporativas. No caso das estatais, o art. $6^{\circ}$ da Lei $n^{\circ} 13.303 / 2016$ determina que devem observar "regras de governança corporativa, de transparência e de estruturas, práticas de 
gestão de riscos e de controle interno, composição da administração". Quanto às instituições financeiras, a Resolução $n^{\circ}$ 4.557/2017 “dispõe sobre a estrutura de gerenciamento de riscos e a estrutura de gerenciamento de capital".

Sendo o uso de softwares necessariamente relacionado à internet, tem-se que o ordenamento brasileiro atual fornece um ambiente normativo propício e relativamente seguro, por meio do Marco Civil da Internet e da recente Lei de Proteção Geral de Dados.

No que diz respeito à análise de riscos, os softwares jurídicos tradicionais têm funções relacionadas ao chamado Business Intelligence, que envolve o tratamento de informações e sua apresentação em diferentes modos, através de gráficos, relatórios e indicadores.

Ainda assim, existe uma ampla gama de programas específicos para análise de riscos, o que foi analisado ao longo do texto. A simples menção às funcionalidades desses programas não permite a compreensão dos efeitos práticos desses instrumentos, de modo que se mostrou interessante uma abordagem mais casuística.

A pesquisa de casos implementada para este trabalho não permite conclusões peremptórias. Mas seu cotejo com os casos analisados permite inferir que a adoção de softwares pelas empresas de alguma forma viabiliza o desenvolvimento da gestão de riscos jurídicos.

\section{REFERÊNCIAS}

BANCO CENTRAL DO BRASIL. Plano Contábil das Instituições do Sistema Financeiro Nacional. Disponível em: https://www.bcb.gov.br/estabilidadefinanceira/cosif. Acesso em 22 jun. 2019.

CONSULTOR JURÍDICO. Conheça os softwares jurídicos mais usados por escritórios e empresas. Acesso em: https://consultorjuridico.jusbrasil.com.br/noticias/201810314/conheca-os-softwares-juridicos-mais-usadospor-escritorios-e-empresas. Disponível em 21 jun. 2019.

CPPROMOBILE. CPPRO. Disponível em: http://cppromobile.novaprolink.com.br/. Acesso em: 21 jun. 2019.

E-XYON. BMG captura processos com a Exyon. Disponível em: https://exyon.com.br/blog/noticias-sobre-e-xyon/bmg-captura-processos-com-exyon. Acesso em: 25 jun. 2019. 
E-XYON. Como a tecnologia jurídica pode ajudar na gestão do risco jurídico. Disponível em: https://e-xyon.com.br/blog/artigos/como-tecnologia-juridica-pode-ajudar-na-gestao-dorisco-juridico. Acesso em: 18 jun. 2019.

E-XYON. Faça um diagnóstico jurídico completo da sua empresa hoje mesmo. Disponível em: https://e-xyon.com.br/blog/artigos/faca-um-diagnostico-juridico-completo-dasua-empresa-hoje-mesmo. Acesso em: 18 jun. 2019.

FACIL. Espaider Coorporativo. Disponível em: https://www.facil.com.br/p.php?ID=1\&T=espaider-corporativo. Acesso em: 21 jun. 2019.

GRILLLO, Brenno Empresas e escritórios discordam sobre melhor software jurídico, aponta pesquisa. Conjur, 23 jan. 2018. Acesso em: https://www.conjur.com.br/2018-jan23/empresas-escritorios-discordam-melhor-software-juridico. Disponível em 21 jun. 2019.

PREAMBULO. Conhecendo os indicadores do CPJ-Analytics. Disponível em: https://www.preambulo.com.br/conhecendo-os-indicadores-do-cpj-analytics/. Acesso em: 21 jun. 2019.

PREAMBULO. CPJ3C. Disponível em: https://www.preambulo.com.br/cpj3c/. Acesso em: 21 jun. 2019.

PREAMBULO. Software jurídico CPJ3C. Disponível em: http://conteudo.preambulo.com.br/software-juridico-cpj3c-

preambulo?_ga=2.112056836.1054718407.1561144680-426651648.1561144680. Acesso em: 21 jun. 2019.

RRSISTEMASJURIDICOS. RR Jurídico. Disponível em: http://www.rrsistemasjuridicos.com.br/site/\#rrjuridico Acesso em: 21 jun. 2019.

SALLOUM SILVA, Emanoel Theodoro. Gestão estratégica do risco legal: fundamentos inerentes à nova economia institucional e compliance. Revista de Direito Empresarial, vol. 6, p. 293-316, Nov-Dez/2014.

SILVA FILHO, Cleoman Fernandes da; GONZALES, Ewerton Zeydir. Análise de risco jurídico e sua relevância para a sedimentação de uma governança corporativa sólida no âmbito das instituições financeiras. Revista de Direito Bancário e do Mercado de Capitais, vol. 72, p. 45-62, Abr-Jun/2016.

SOFTPLAN. Departamento Jurídico como centro de resultados. Disponível em: https://www.softplan.com.br/convex/. Acesso em: 21 jun. 2019.

SOFTPLAN. O Convex atende escritórios e departamentos jurídicos. Disponível em: https://www.softplan.com.br/convex/cases/. Acesso em: 21 jun. 2019.

TGN BRASIL. Corsan aprimora gestão de riscos e governança com a SoftExpert. Disponível em: https://tgnbrasil.com.br/corsan-aprimora-gestao-de-riscos-e-governanca-coma-softexpert/. Acesso em: 18 jun. 2019. 
TGN BRASIL. Soluções para Excelência na Gestão e Conformidade Empresarial. Disponível em: https://tgnbrasil.com.br/. Acesso em 18 jun. 2019.

TGN BRASIL. Unimed Vitória aumenta a eficácia de seus processos com as soluções SoftExpert. Disponível em: https://tgnbrasil.com.br/unimed-vitoria-case-de-sucesso/. Acesso em: 18 jun. 2019.

THOMSON REUTERS. Legal One Corporate: sua prática jurídica em um novo nível. Disponível em: https://www.thomsonreuters.com.br/content/dam/openweb/documents/pdf/Brazil/whitepaper/legal-one-corporate.pdf Acesso em 18 jun. 2019.

THOMSON REUTERS. Legal One. Disponível em: https://www.thomsonreuters.com.br/pt/juridico/legal-one.html. Acesso em 18 jun. 2019.

1 SALLOUM SILVA, Emanoel Theodoro. Gestão estratégica do risco legal: fundamentos inerentes à nova economia institucional e compliance. Revista de Direito Empresarial, vol. 6, p. 293-316, Nov-Dez/2014. p. 2.

${ }^{2}$ SALLOUM SILVA, Emanoel Theodoro. Gestão... p. 3.

${ }^{3}$ SALLOUM SILVA, Emanoel Theodoro. Gestão... p. 10.

${ }^{4}$ SALLOUM SILVA, Emanoel Theodoro. Gestão... p. 11.

${ }^{5}$ SALLOUM SILVA, Emanoel Theodoro. Gestão... p. 14-15

${ }^{6}$ SALLOUM SILVA, Emanoel Theodoro. Gestão...

7 BANCO CENTRAL DO BRASIL. Plano Contábil das Instituições do Sistema Financeiro Nacional.

Disponível em: https://www.bcb.gov.br/estabilidadefinanceira/cosif. Acesso em 22 jun. 2019.

${ }^{8}$ SALLOUM SILVA, Emanoel Theodoro. Gestão...p. 2.

${ }^{9}$ SILVA FILHO, Cleoman Fernandes da; GONZALES, Ewerton Zeydir. Análise... p. 2.

${ }^{10}$ SILVA FILHO, Cleoman Fernandes da; GONZALES, Ewerton Zeydir. Análise... p. 5.

${ }^{11}$ SILVA FILHO, Cleoman Fernandes da; GONZALES, Ewerton Zeydir. Análise... p. 4.

12 SALLOUM SILVA, Emanoel Theodoro. Gestão...p. 4.

${ }^{13}$ SILVA FILHO, Cleoman Fernandes da; GONZALES, Ewerton Zeydir. Análise... p. 12.

${ }^{14}$ SALLOUM SILVA, Emanoel Theodoro. Gestão... p. 14

15 SALLOUM SILVA, Emanoel Theodoro. Gestão... p. 5.

16 SALLOUM SILVA, Emanoel Theodoro. Gestão... p. 6.

${ }^{17}$ SILVA FILHO, Cleoman Fernandes da; GONZALES, Ewerton Zeydir. Análise... p. 8.

${ }_{18}$ SILVA FILHO, Cleoman Fernandes da; GONZALES, Ewerton Zeydir. Análise... p. 7.

${ }^{19}$ CONSULTOR JURÍDICO. Conheça os softwares jurídicos mais usados por escritórios e empresas. Disponível em: https://consultor-juridico.jusbrasil.com.br/noticias/201810314/conheca-os-softwares-juridicosmais-usados-por-escritorios-e-empresas. Acesso em: 21 jun. 2019.

${ }^{20}$ GRILLLO, Brenno Empresas e escritórios discordam sobre melhor software jurídico, aponta pesquisa. Conjur, 23 jan. 2018. Disponível em: https://www.conjur.com.br/2018-jan-23/empresas-escritorios-discordammelhor-software-juridico. Acesso em: 21 jun. 2019.

${ }^{21}$ A pesquisa adverte que o total passa de $100 \%$ porque era possível escolher mais de um software.

22 FACIL. Espaider Coorporativo. Disponível em: https://www.facil.com.br/p.php?ID=1\&T=espaidercorporativo. Acesso em: 21 jun. 2019.

${ }_{23}$ RRSISTEMASJURIDICOS. RR Jurídico. http://www.rrsistemasjuridicos.com.br/site/\#rrjuridico Acesso em: 21 jun. 2019.

${ }^{24}$ RRSISTEMASJURIDICOS. RR Jurídico...

${ }^{25}$ PREAMBULO. CPJ3C. Disponível em: https://www.preambulo.com.br/cpj3c/. Acesso em: 21 jun. 2019.

${ }^{26}$ PREAMBULO. Software jurídico CPJ3C. Disponível em: http://conteudo.preambulo.com.br/softwarejuridico-cpj3c-preambulo?_ga=2.112056836.1054718407.1561144680-426651648.1561144680. Acesso em: 21 jun. 2019.

${ }^{27}$ CPPROMOBILE. CPPRO. Disponível em: http://cppromobile.novaprolink.com.br/. Acesso em: 21 jun. 2019. 
28 FACIL. Espaider Coorporativo. Disponível em: https://www.facil.com.br/p.php?ID=1\&T=espaidercorporativo. Acesso em: 21 jun. 2019.

29 PREAMBULO. Conhecendo os indicadores do CPJ-Analytics. Disponível em: https://www.preambulo.com.br/conhecendo-os-indicadores-do-cpj-analytics/. Acesso em: 21 jun. 2019.

30 THOMSON REUTERS. Legal One. Disponível em: https://www.thomsonreuters.com.br/pt/juridico/legalone.html. Acesso em 18 jun. 2019.

31 SOFTPLAN. Departamento Jurídico como centro de resultados. Disponível em: https://www.softplan.com.br/convex/. Acesso em: 21 jun. 2019.

32 SOFTPLAN. O Convex atende escritórios e departamentos jurídicos. Disponível em: https://www.softplan.com.br/convex/cases/. Acesso em: 21 jun. 2019.

${ }_{33}$ TGN BRASIL. Soluções para Excelência na Gestão e Conformidade Empresarial. Disponível em: https://tgnbrasil.com.br/. Acesso em 18 jun. 2019.

34 TGN BRASIL. Corsan aprimora gestão de riscos e governança com a SoftExpert. Disponível em: https://tgnbrasil.com.br/corsan-aprimora-gestao-de-riscos-e-governanca-com-a-softexpert/. Acesso em 18 jun. 2019.

${ }^{35}$ TGN BRASIL. Corsan aprimora...

${ }^{36}$ CERTIFICACAOISO. O que é SGQ? Disponível em: https://certificacaoiso.com.br/e-sgq/. Acesso em: 18 jun. 2019.

37 TGN BRASIL. Unimed Vitória aumenta a eficácia de seus processos com as soluções SoftExpert. Disponível em: https://tgnbrasil.com.br/unimed-vitoria-case-de-sucesso/. Acesso em 18 jun. 2019.

${ }^{38} \mathrm{E}-\mathrm{XYON}$. Como a tecnologia jurídica pode ajudar na gestão do risco jurídico. Disponível em: https://exyon.com.br/blog/artigos/como-tecnologia-juridica-pode-ajudar-na-gestao-do-risco-juridico. Acesso em: 18 jun. 2019.

${ }^{39}$ E-XYON. BMG captura processos com a Exyon. Disponível em: https://e-xyon.com.br/blog/noticias-sobree-xyon/bmg-captura-processos-com-exyon. Acesso em: 25 jun. 2019. 